\title{
RESEARCH
}

\section{EFFECTS OF OUTDOOR NATURAL LIGHT EXPOSURE ON SLEEP QUALITY IN THE ELDERLY}

Turkish Journal of Geriatrics

DOI: 10.31086/tjgeri.2020.147

2020; 23(1): 138-146

- Kenan Eren ŞANSAL ${ }^{1}$

- Sezin Hatice TANRIÖVER ${ }^{1}$ (D)

- Başak TÜRKÜLER AKA²

\section{CORRESPONDANCE}

Kenan Eren ŞANSAL

Bahçeşehir University, Interior Architecture and

Environmental Design, İstanbul, TURKEY.

Phone: +905343659277

e-mail: erensansal@gmail.com

Received: 22/11/2019

Accepted: 17/12/2019

\section{Abstract}

Introduction: One of the serious outcomes associated with ageing is the high prevalence of age-related sleep disturbances detrimentally influencing general well-being in the elderly. Whilst underexposure to diurnal bright light appears to be a reason for disturbed sleep in old age, further empirical evidence is required to confirm such a relationship.

Materials and Method: In order to contribute to our current understanding of the subject, a study was conducted in a long-term care facility in Istanbul, Turkey. Participating elderly residents $(\mathrm{N}=39)$ were exposed to natural light outdoors (> $10,000 \mathrm{~lx}$ ) for 40 minutes in the morning on 17-21 June and 1-5 July 2019, and they were asked to report on their sleep quality by completing various questionnaires throughout the study.

Results: The results of the study demonstrated a significant difference ( $p<$ 0.05 ) between the pre- and post-treatment scores of the participants. Moreover, the participants reported significantly less $(p<0.05)$ disturbed sleep in the second period during which they were exposed to approximately $63 \%$ more natural light.

Conclusion: Based on our findings and those of other research groups, it is possible to conclude that light, or more specifically natural light, should be considered as an independent factor affecting sleep and, thus, general well-being in old age.

Keywords: Light; Sunlight; Sleep; Aged; Aging.
Bahçeşehir University, Interior Architecture and Environmental Design, İstanbul, TURKEY.

${ }^{2}$ Bahçeşehir University, Psychology, İstanbul, TURKEY. 


\section{INTRODUCTION}

In people aged 65 and above, a major change often accompanying the ageing process is the disruption of the daily sleep-wake cycle (1). There is ample evidence from epidemiological studies that sleep-related problems become more prevalent and severe as age advances. Approximately 50\% of community-dwelling elderly and $67 \%$ of those residing in long-term care facilities have been reported to have considerable difficulties in initiating and maintaining sleep (2). There are serious consequences of disturbed sleep for the elderly such as increased risk of falling, decreased physical functioning, impaired memory and heightened mortality (3). Thus, improving sleep in older adults is key to a high quality life and good daytime functioning.

In humans, sleep and wakefulness are governed by the following two largely independent mechanisms: a) the homeostatic drive to sleep and b) the circadian system controlling diurnal oscillations (4). On one hand, the homeostatic sleep drive is determined by the time spent awake or the duration of previous sleep. The longer we stay awake, the more our sleep propensity increases. On the other hand, the circadian system synchronises the daily sleep-wake cycle and other biological rhythms with a number of exogenous temporal cues termed as zeitgebers. Whilst light is considered to be the principle zeitgeber in humans (5), its effectiveness differs with age. To elicit the same circadian response, a 65-year-old elderly adult needs roughly three times more light than a 25 -year-old young adult due to crystalline lens yellowing and pupillary miosis (6).

Given the impact of ageing on the photic entrainment of our circadian rhythms, it can be postulated that there may be a close association between sleep disturbances and the amount of light exposure amongst the elderly, especially those living in long-term care facilities. According to the research on the subject, it should be noted that older adults spend only less than 1 hour at high illuminance levels exceeding 1,000 lx in a day (7). However, one should not leap to the conclusion that insufficient or limited exposure to an optimal light level is an independent risk factor for sleep disturbance. A review of the existing literature reveals that there are inconsistencies and discrepancies in the reported findings.

On one hand, some of the studies discredit the possible role of light, or more specifically diurnal bright light exposure. For example, Dowling and colleagues (8) observed that 1-hour exposure to light levels higher than 2,500 $\mathrm{lx}$ in the morning for 10 weeks could not influence sleep initiation and maintenance in a sample of institutionalised patients with Alzheimer's disease. On the other hand, a number of studies suggest the potency of natural light or illuminances is considerably higher than those commonly experienced indoors. The major problem with the latter studies is that the minimum amount and duration of light exposure necessary to improve and restore sleep cannot be specified. In one of these studies, Hood and colleagues (9) demonstrated that there was a significant relationship between the duration of exposure to illuminances over 3,000 Ix and the nocturnal immobility amongst a sample of healthy aged participants. This finding is not in complete accord with the results obtained by Shochat and colleagues (7). Unlike the other research group, they were not able to identify a critical threshold. Higher light levels predicted fewer night-time awakenings in a nursing home population. Two other studies revealed that even a very brief exposure to outdoor illumination conditions may also be beneficial (10, 11). Exposing nursing home residents to natural light outdoors or extremely high levels more than 10,000 Ix for 30-60 minutes generally in the morning was shown to be useful to ameliorate sleep disturbances.

Because of the above-mentioned discrepancies and methodological differences in the literature, it 
is still not possible to state with certainty that the low daily light dose received by the elderly can detrimentally influence their sleep. Until we have a sound understanding of the effects of light on our sleep-wake rhythm, there is a compelling need to determine whether such a causal relationship exists. Therefore, in an attempt to build on the earlier work and contribute to our limited knowledge about the subject, this study was conducted in a long-term care facility over a 1-month period. The present paper reports the results of this investigation carried out to test the following hypotheses:

a) Elderly home residents have considerable difficulties in initiating and maintaining sleep and, as a direct consequence, have poor sleep quality.

b) Diurnal bright light exposure can alleviate sleep disturbances and, thus, improve sleep quality of the residents.

\section{MATERIALS AND METHOD}

\subsection{Participants}

A total of 43 (37 females and 6 males) elderly adults, who had been residing in an eldercare facility located in Istanbul for more than 6 months, voluntarily participated in the study. Of those participants, four females were excluded since they were experiencing difficulties in following the study protocol. All remaining participants were

a) older than 65 years (mean $\pm \mathrm{SD}=80.23 \pm 5.19$ );

b) literate and had at least completed primary school education;

c) cognitively intact. Four weeks prior to the study, a general estimate of residents' cognitive status was obtained by administering a Turkish version of the Standardised Mini Mental State Examination (SMMSE) (12). This brief test comprises various questions and tasks that assess several domains of cognitive function. Whilst an SMMSE score of 30 indicates no impairment, scores between 26 and 30 are considered to be normal in the general population. Gungen and colleagues (13) translated the SMMSE into Turkish and recommended $23 / 24$ as the cut-off score for reliably and validly diagnosing dementia with its Turkish version (SMMSE-T). Therefore, the residents who had scored less than 23 were screened out. The mean \pm SD SMMSE-T score of the participants was $26.64 \pm 2.75$;

d) considered to be healthy on the basis of their medical records and scores on a general health profile. For profiling purposes, a Turkish version of the Short Form 36 (SF-36) (14) was self-administered by the residents to report on their physical and mental health status before the study. The SF-36 is a 36-item generic measure developed to determine perceived health transition and assess eight domains of health. For each domain evaluated, respective item scores are recoded, summed and transformed into a scale from zero, indicating an extreme disturbance, to 100 , indicating no disturbance. Kocyigit and colleagues (15) translated the SF-36 into Turkish and reported that the psychometric properties of its Turkish version (SF-36T) were acceptable. Norms for SF-36T scores in the elderly (16) were compared with participants' scores. Whilst there were no significant differences between the role limitations because of physical health problems, bodily pain, general health perceptions, vitality and social functioning domain scores, it was observed that our participants had significantly better physical function [t(152) $=-2.74 ; p<0.05]$ and general mental health $[t(152)=-2.18 ; p<0.05]$. The only dimension score that was found to be significantly lower in our sample was for the role limitations because of emotional problems domain $[\mathrm{t}(152)=2.09 ; \mathrm{p}$ $<0.05]$;

e) moderately morning-type, intermediate-type or moderately evening-type individuals. Apart from the above-mentioned measures, a Turk- 
ish version of the Morningness-Eveningness Questionnaire (MEQ) (17) was also used to determine participants' chronotype. The MEQ is a self-administered questionnaire that consists of 19 items rated on a four-point Likert-type scale or a scale with various time intervals. An MEQ score, ranging from 16 to 86 , is obtained by adding all item scores, and it is utilised to identify chronotypes. Agargun and colleagues (18) translated the MEQ into Turkish and demonstrated that its Turkish version (MEQ-T) was reliable and valid. To ensure compliance with the study protocol, evening-type residents who had scored between 16 and 30 were excluded from the study sample. The mean \pm SD MEQ-T score of the participants was $57.97 \pm 7.30$.

In accordance with the Declaration of Helsin$\mathrm{ki}$ and ethical clearance received from the Ethics Committee of our university, consent was obtained from each participant. Even though all participants were thoroughly informed about their rights and responsibilities, no information on possible study outcomes was given to minimise confounding effects of prior knowledge and expectations.

\subsection{Sleep Assessment}

\subsubsection{Pittsburgh Sleep Quality Index}

A Turkish version of the Pittsburgh Sleep Quality Index (PSOI) (19) was completed by the residents to assess their nocturnal sleep. The PSOI is a self-administered questionnaire developed to differentiate 'good' from 'poor' sleepers by evaluating sleep quality and disturbances in the preceding month. It consists of 19 self-report items and five additional items for the bed partner or roommate. Only the self-report items are used in the scoring of the PSQI. Responses to these items are grouped to obtain seven component scores. Each component score ranges from zero, indicating no difficulty, to three, indicating severe difficulty. A global PSQl score, varying from zero to 21, can also be obtained by adding the component scores. A global score greater than five was report- ed to provide a sensitive and specific measure of poor sleep quality. Agargun and colleagues (20) translated the PSOI into Turkish and reported that the psychometric properties of its Turkish version (PSQI-T) were satisfactory.

\subsubsection{PROMIS Sleep Disturbance Short Form}

Additionally, the participants filled in a Turkish version of the PROMIS Sleep Disturbance Short Form (PSDSF) (21). The PSDSF is a self-administered questionnaire devised to assess qualitative aspects of sleep over the last seven days. Eight items of the questionnaire are rated on a Likerttype scale ranging from one, not at all, to five, very much. A raw PSDSF score is obtained by adding all item scores, and it is used in order to estimate the corresponding $t$ score. The $t$ scores vary from 28.9 to 76.5 , and they are interpreted as follows: less than 50, none to slight sleep disturbance; between 55.0 and 59.9, mild sleep disturbance; between 60.0 and 69.9, moderate sleep disturbance; 70 and over, severe sleep disturbance. Yuzeren and colleagues (22) translated the PSDSF into Turkish and provided evidence that its Turkish version (PSDSF-T) reliably and validly represents sleep disturbances in a sample of healthy and sleep-disturbed adults.

\subsubsection{Richards-Campbell Sleep Questionnaire}

Since there was a need for a measure to assess previous night's sleep, a Turkish version of the Richards-Campbell Sleep Questionnaire (RCSO) (23) was also used. The RCSO is a brief, five-item questionnaire developed to evaluate perceived sleep depth, latency, fragmentation, efficiency and quality in an acute care setting. For each item, respondents were asked to rate their sleep the previous night on a $100 \mathrm{~mm}$ visual analogue scale with two anchor points. An RCSO score can be obtained by calculating the mean of all item scores ranging from zero to 100 . Although there is no cutoff score for the questionnaire, a high mean score is indicative of subjective sleep satisfaction. Ozlu 
and Ozer (24) translated the RCSO into Turkish and demonstrated that its Turkish version (RCSQ-T) was reliable and valid.

\subsection{Procedure}

The study was conducted between 17 June and 15 July 2019. Over two five-day periods (Figure 1), during which the atmospheric and lighting conditions differed markedly, the participating residents were taken outside the nursing home at 9:00 AM. Whilst the participants were assessing their sleep, they were exposed to natural light in each morning for 40 minutes (see Table 1 for the tasks carried out throughout the study period). To gain insight of the pre-existing and post-treatment sleep quality of the study population, the PSOI-T was administered on the first and last days of the study. On 17-22 June and 1-6 July 2019, each participant filled in the RCSQ-T at 9:00 AM to report their previous night's sleep. Additionally, the participants evaluated their sleep through the PSDSF-T on 1 and 15 July 2019 to assess whether possible effects of the bright light exposure would carry over into the following weeks. It is important to note here that, instead of identifying trait sleep problems, the above-mentioned questionnaires had been devised to assess monthly, weekly or daily variations in sleep quality. Therefore, it was assumed that minimal or no habituation would be elicited from the participants repeatedly rating their sleep over the course of the study.

In each period, vertical illuminance levels at participants' sitting eye height (approximately at $120 \mathrm{~cm}$ ) were also measured daily between 9:00 and 9:40 AM at 20-minute intervals in the cardinal compass directions (N, S, E and W). All measurements were carried out with a portable illuminance metre (model BF05; Trotec GmbH \& Co., Heinsberg, Germany).

Figure 1. Dates and times for the two exposure periods.

\begin{tabular}{|c|c|c|c|c|c|c|c|c|c|c|c|c|c|c|c|c|c|c|c|c|c|c|c|c|c|c|c|c|}
\hline \multicolumn{14}{|c|}{ Exposure Period 1} & \multicolumn{15}{|c|}{ Exposure Period 2} \\
\hline \multicolumn{5}{|c|}{ ৭:00-9:40 AM } & & & & & & & & & & \multicolumn{5}{|c|}{ ৭:00-9:40 AM } & \multirow[b]{2}{*}{6} & \multirow[b]{2}{*}{7} & \multirow[b]{2}{*}{8} & \multirow[b]{2}{*}{9} & \multirow[b]{2}{*}{10} & \multirow[b]{2}{*}{11} & \multirow[b]{2}{*}{12} & \multirow[b]{2}{*}{13} & \multirow[b]{2}{*}{14} & \multirow[b]{2}{*}{15} \\
\hline 17 & 18 & 19 & 20 & 21 & 22 & 23 & 24 & 25 & 26 & 27 & 28 & 29 & 30 & 1 & 2 & 3 & 4 & 5 & & & & & & & & & & \\
\hline \multicolumn{14}{|c|}{ June } & \multicolumn{15}{|c|}{ July } \\
\hline & & & & & & & & & & & & & & 2019 & & & & & & & & & & & & & & \\
\hline
\end{tabular}

Table 1. Tasks carried out throughout the study period.

\begin{tabular}{|l|l|}
\hline Date & Task \\
\hline $17-21$ June and 1-5 July 2019 & 40-minute morning bright light exposure \\
\hline 17 June and 15 July 2019 & PSQI-T administration at 09:00 AM \\
\hline $17-22$ June and 1-6 July 2019 & RCSQ-T administration at 09:00 AM \\
\hline 1 and 15 July 2019 & PSDSF-T administration at 09:00 AM \\
\hline
\end{tabular}




\subsection{Statistical Analysis}

Paired-samples (or dependent-samples) t-tests were performed in order to analyse the statistical differences between participants' PSQI-T, PSDSF-T and RCSQ-T scores. The rationale of comparison and comparison groups are presented in Table 2. It is evident from the table that four separate analyses were carried out for comparing: a) the total mean RCSQ-T scores for the two exposure periods; b) the mean RCSQ-T scores for the two nights before each exposure period; $c$ ) the mean PSDSF-T scores for the two weeks following the end of each exposure period; and d) the mean PSOI-T scores obtained on the first and last day of the whole study period. These statistical analyses were per- formed with the SPSS Statistical Software Package for Windows (version 20.0; SPSS Inc., Chicago, IL, USA). The statistical analyses to compare sample mean differences in the SF-36T scores were carried out with MedCalc for Windows (version 15.0; MedCalc Software, Ostend, Belgium). The level of significance was set at $p<0.05$.

\section{Results}

\subsection{Light}

The calculated average illuminances to which the elderly were exposed during each exposure period are presented in Figures $2 \mathrm{a}$ and $2 \mathrm{~b}$. It can be seen from these figures that there are considerable differences. Due to the overcast sky and, as a

Table 2. TFour separate analyses performed for participants' PSQI-T, PSDSF-T and RCSQ-T scores.

\begin{tabular}{|l|l|l|}
\hline Measure & Comparison Groups & Rationale \\
\hline RCSQ-T & $\begin{array}{l}\text { The total mean scores for the nights of 17-21 } \\
\text { June and 1-5 July 2019 }\end{array}$ & To check the effect of daylight exposure \\
\hline RCSQ-T & $\begin{array}{l}\text { The mean scores for the nights of 16 and 30 } \\
\text { June } 2019\end{array}$ & $\begin{array}{l}\text { To check whether the sleep quality levels were } \\
\text { equivalent at the beginning of each exposure } \\
\text { period }\end{array}$ \\
\hline PSDSF-T & $\begin{array}{l}\text { The mean scores obtained on } 1 \text { and } 15 \text { July } \\
2019\end{array}$ & $\begin{array}{l}\text { To check whether there was a carry-over effect } \\
\text { of daylight exposure }\end{array}$ \\
\hline PSQI-T & $\begin{array}{l}\text { The mean scores obtained on } 17 \text { June and } 15 \\
\text { July } 2019\end{array}$ & $\begin{array}{l}\text { To check pre-existing and post treatment } \\
\text { sleep quality and assess the exposure effect }\end{array}$ \\
\hline
\end{tabular}

Figure $\mathbf{2 a}$ and $\mathbf{2 b}$. Average vertical illuminances for each period.

A. Illuminances for Period 1

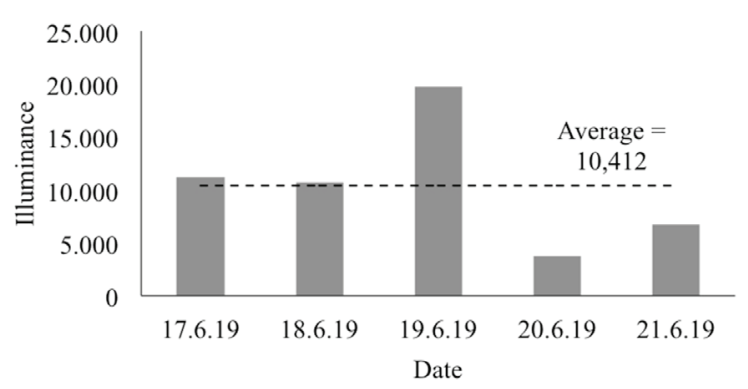

B. Illuminances for Period 2

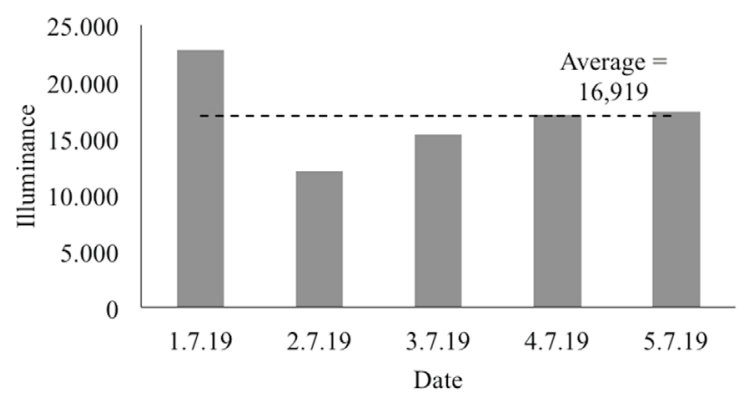


direct consequence, relatively low illuminances on 20 and 21 June 2019, the elderly were exposed to an average illuminance of $10,412 \mathrm{~lx}$ in the first period. Since the sky was mostly clear between 1 and 5 July 2019, the average illuminance exposure over the second period was $16,919 \mathrm{~lx}$ and approximately $63 \%$ higher than that in the first period.

\subsection{Sleep Quality}

In order to assess the pre-existing and post-treatment sleep quality of the study population, a comparison between the mean scores obtained for the first and second PSOI-T administrations was done. The results obtained were in support of our first and second hypotheses. Participants' initial score (mean $\pm \mathrm{SD}=6.10 \pm 3.13$ ) was found to be above the cut-off for poor sleep quality and significantly higher $[\mathrm{t}(38)=2.93 ; \mathrm{p}<$ $0.05]$ than their score at the end of the study period (mean $\pm \mathrm{SD}=4.92 \pm 2.99$ ) (Figure 3a).

With the aim of understanding whether the observed improvement in sleep could be directly attributable to light, a further analysis was performed by comparing the mean RCSQ-T scores calculated for the five nights following the exposure to light outdoors. The analysis result was in favour with our second hypothesis. The score for the second period (mean $\pm S D=77.79 \pm 13.00$ ) was significantly higher $[t(38)=-2.30 ; p<0.05]$ than the one for the first period (mean $\pm \mathrm{SD}=73.02 \pm 15.59$ ) (Figure 3b). To rule out the possibility that the effects of bright light exposure in the first period could carry over and account for this statistically significant difference, the initial mean RCSQ-T scores for the nights of 16 and 30 June 2019 were compared. Additionally, the mean PSDSF-T scores for the weeks after each exposure period were also compared with the same rationale. It was evident from the results that there were no statistically significant differences.

\section{DISCUSSION}

One of the questions that need to be answered by future research is whether sleep problems and light exposure in older adults are closely linked. Our findings suggest that light, or more specifically natural light, itself is a potent external stimulus for the daily sleep-wake cycle of the elderly. Even though our sample had less difficulty in initiating and maintaining sleep than those from other studies conducted at similar facilities in Turkey (25), there was a significant difference between preand post-treatment PSOI-T scores. This finding is in complete accord with the observations from some of the earlier research efforts. Like Alessi et al. (10) and another Turkish research group (11), it was demonstrated by the present study that ex-

Figure 3a and 3b. Participants' mean \pm SD PSQI-T scores and their mean \pm SD RCSQ-T scores for each period .

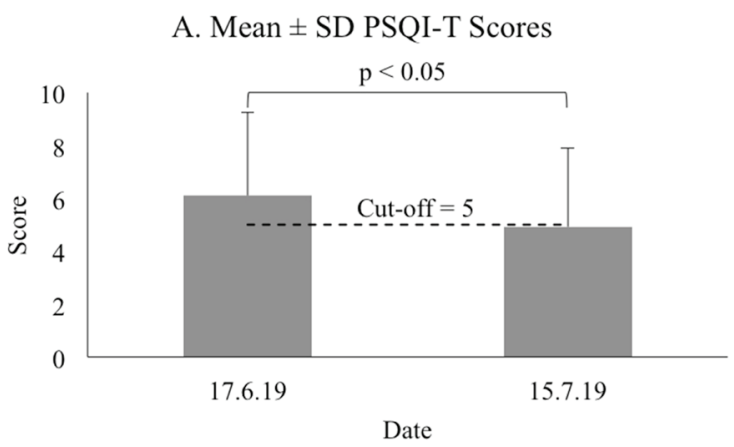

Date
B. Mean \pm SD RCSQ-T Scores

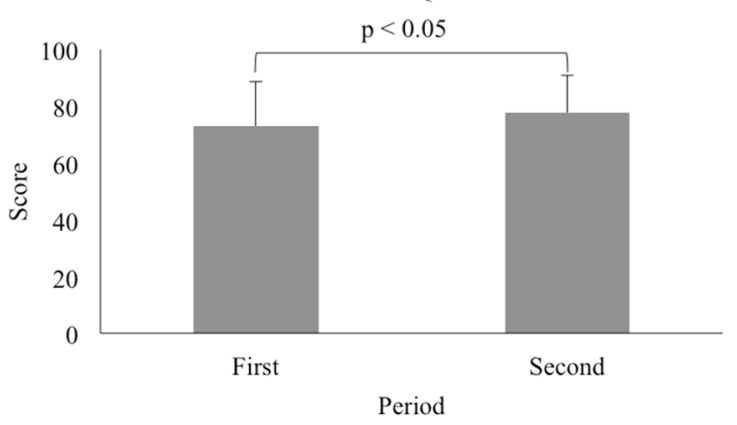


posure to natural light outdoors or very high illuminance levels for a brief period in the morning over five consecutive days could be beneficial to the sleep quality in older adults.

It should be noted here that on the basis of our findings, it would be erroneous to state an illuminance threshold or duration necessary to promote a healthy circadian response. Although exposing the participants to an average illuminance of approximately 17,000 Ix for 40 minutes over a fiveday period (Exposure Period 2) was observed to be more effective than the exposure to roughly 63\% less daylight ( 10,000 Ix) for the same length (Exposure Period 1), it is not possible to state whether increasing exposure duration for much lower levels $(<10,000 \mathrm{~lx})$ may yield similar results. For example, Hood and colleagues (9) reported that nocturnal immobility was positively correlated with the duration of exposure to levels over 3,000 Ix. Moreover, it is not completely clear when the expected effects of natural or bright light exposure would wear off. Given the insignificant differences in the PSDSF-T and RCSQ-T scores obtained on the first day of each period, it is plausible to suppose that the exposure effects may last not more than a few days following light exposure and, thus, should only be expected for a short period in the elderly. However, it is unlikely to state with certainty what the exact effect duration can be.

There are a number of limitations that should be taken into account in interpreting the above-mentioned results and conducting future research. Firstly, possible gender effects on the study outcomes cannot be ruled out due to the scarcity of male residents in the facility and, as a direct consequence, relatively high number of females (33 females versus 6 males) in our sample. Secondly, the necessities of old age made it difficult to recruit participants who were not on medication. Despite being free from any prescribed sleep medication, the participants were taking medications, such as beta-blockers or diuretics, known to interfere with sleep. Thirdly, it is not clear to what extent the results obtained were influenced by the presence of depressed mood in our sample. In spite of the acknowledged association between depression and disturbed sleep in the elderly, participants' depression status could not be examined in the facility because of not being granted an official permission to use any measure diagnosing psychiatric illnesses. Therefore, the results of the present study should be considered accordingly.

Evidently, more interdisciplinary research in the fields of health care and architectural design is required to fully understand the non-visual effects of light. Nonetheless, it is already possible to draw some conclusions from the results discussed above. Firstly, given that diurnal bright light exposure can be a treatment or treatment adjunct for age-related sleep problems, a suitable approach to lighting design in long-term care facilities is to utilise the sun as the main source of daytime illumination. By adopting this approach, we may not only reduce our current dependency on electric light sources but also improve the well-being and overall life quality of elderly residents. Secondly, it seems reasonable to suggest that spending a substantial portion of a day in dimly lit environments virtually devoid of natural light is likely to be detrimental to sleep in older adults and, thus, should be avoided.

\section{ACKNOWLEDGEMENT}

We would like to thank Zeynep Hilal Celik, Ece Kurtoglu and Deniz Eyuce Sansal for their invaluable assistance in collecting data. We are also extremely grateful to our participants and the facility administration for their help and support. Lastly, we wish to thank the anonymous reviewers for their constructive comments and valuable suggestions.

\section{CONFLICT OF INTEREST}

The authors declare no conflict of interest. 


\section{REFERENCES}

1. Vitiello MV. Sleep in normal aging. Sleep Med Clin 2006;1(2):171-6.

2. Haesler EJ. Effectiveness of strategies to manage sleep in residents of aged care facilities. JBI Libr Syst Rev 2004;2(4):1-107. (PMID:27820000).

3. Neikrug AB, Ancoli-Israel S. Sleep disorders in the older adult: A mini-review. Gerontology 2010;56(2):181-9. (PMID:19738366).

4. Stanley N. The physiology of sleep and the impact of ageing. Eur Urol Suppl 2005;3(6):17-23.

5. Klerman EB, Rimmer DW, Dijk D, Kronauer RE, Rizzo JF, Czeisler CA. Nonphotic entrainment of the human circadian pacemaker. Am J Physiol 1998;274(4 Pt 2):R991-6. (PMID:9575961).

6. Turner PL, Mainster MA. (2008). Circadian photoreception: Ageing and the eye's important role in systemic health. Br J Ophthalmol 2008;92(11):143944. (PMID:18757473).

7. Shochat T, Martin J, Marler M, Ancoli-Israel S. Illumination levels in nursing home patients: Effects on sleep and activity rhythms. J Sleep Res 2000;9(4):37379. (PMID:11386204).

8. Dowling GA, Burr RL, Van Someren EJW, et al. Melatonin and bright-light treatment for restactivity disruption in institutionalized patients with Alzheimer's disease. J Am Geriatr Soc 2008;56(2):23946. (PMID:18070004).

9. Hood B, Bruck D, Kennedy G. Determinants of sleep quality in the healthy aged: The role of physical, psychological, circadian and naturalistic light variables. Age Ageing 2004;33(2):159-65. (PMID:14960432).

10. Alessi CA, Martin JL, Webber AP, Kim EC, Harker JO, Josephson KR. Randomized, controlled trial of a nonpharmacological intervention to improve abnormal sleep/wake patterns in nursing home residents. J Am Geriatr Soc 2005;53(5):803-10. (PMID:15877555).

11. Duzgun G, Akyol AD. Effect of natural sunlight on sleep problems and sleep quality of the elderly staying in the nursing home. Holist Nurs Pract 2017;31(5):295302. (PMID:28786887).

12. Molloy DW, Alemayehu E, Roberts R. Reliability of a Standardized Mini-Mental Examination compared with the traditional Mini-Mental State Examination. Am J Psychiatry 1991;148(1):102-5. (PMID:1984692).

13. Gungen C, Ertan T, Eker E, Yasar R, Engin F. Reliability and validity of the standardized Mini Mental State
Examination in the diagnosis of mild dementia in Turkish population. Turk Psikiyatri Derg 2002;13(4):27381. (PMID:12794644).

14. Ware JE, Sherbourne CD. The MOS 36-item shortform health survey (SF-36): I. Conceptual framework and item selection. Med Care 1992;30(6):473-83. (PMID:1593914).

15. Kocyigit $\mathrm{H}$, Aydemir O, Fisek G, Olmez N, Memis A. The validity and reliability of Turkish version of the Short Form 36 (SF-36). Ilac ve Tedavi Derg 1999;12(2):102-106.

16. Demiral $Y$, Ergor G, Unal B, et al. Normative data and discriminative properties of short form 36 (SF36) in Turkish urban population. BMC Public Health 2006;6:247. (PMID:17029646).

17. Horne JA, Ostberg O. A self-assessment questionnaire to determine morningness-eveningness in human circadian rhythms. Int J Chronobiol 1976; 4(2):97-110. (PMID:1027738).

18. Agargun MY, Cilli AS, Boysan, M, Selvi Y, Gulec M, Kara $\mathrm{H}$. Turkish version of morningness-eveningness questionnaire (MEQ). Sleep Hypn 2007;9(1):16-23.

19. Buysse DJ, Reynolds CF, Monk TH, Berman SR, Kupfer DJ. The Pittsburg Sleep Quality Index: A new instrument for psychiatric practice and research. Psychiatry Res 1989;28(2):193-213. (PMID:2748771).

20. Agargun MY, Kara $H$, Anlar $O$. The validity and reliability of the Pittsburgh Sleep Quality Index. Turk Psikiyatri Derg 1996;7(2):107-15.

21. Yu L, Buysse DJ, Germain A, et al. Development of short forms from the PROMIS sleep disturbance and sleep-related impairment item banks. Behav Sleep Med 2012;10(1):6-24. (PMID:22250775).

22. Yuzeren S, Herdem A, Aydemir O, DSM-5 Olcek Calisma Grubu. Reliability and validity of Turkish form of Sleep Disorder Scale. Anadolu Psikiyatri Derg 2017;18(Supplement 2):79-84.

23. Richards KC, O'sullivan PS, Phillips RL. Measurement of sleep in critically ill patients. J Nurs Meas 2000;8(2):131-44. (PMID: 11227580).

24. Ozlu ZK, Ozer N. Richard-Campbell Sleep Questionnaire validity and reliability study. J Turk Sleep Med 2015; 2(2):29-32.

25. Fadiloglu C, Ilkbay Y, Yildirim YK. Sleep quality among nursing home residents. Turkish Journal of Geriatrics 2006;9(3):165-169. 